\title{
Simulation of dry matter production and distribution in cassava (Manihot esculenta Crantz)
}

\author{
H. GIJZEN', H. J. VELTKAMP², J. GOUDRIAAN³ \& G. H. DE BRUIJN ${ }^{4}$ \\ 1 Centre for Agrobiological Research, P.O. Box 14, NL 6700 AA Wageningen, Netherlands \\ 2 International Agricultural College Larenstein, P.O. Box 7, NL 7400 AA Deventer, \\ Netherlands \\ ${ }^{3}$ Department of Theoretical Production Ecology, Wageningen Agricultural University, \\ P.O. Box 430, NL 6700 AK Wageningen, Netherlands \\ 4 Department of Tropical Crop Science, Wageningen Agricultural University, P.O. Box \\ 341, NL 6700 AK Wageningen, Netherlands
}

Received 15 September 1989; accepted 16 March 1990

\begin{abstract}
In order to contribute to the development of a growth model of cassava with wider applicability than models used so far, the dry matter production of a number of cassava cultivars was simulated with a modified version of the SUCROS model. The overall behaviour of the model was validated with data from periodic harvests. The costs of maintenance respiration of stems and leaves were adjusted by curve fitting using data from one of the experiments. Agreement between experimental and model results was generally good. The model describes basic physiological processes and can be used to simulate growth of different cultivars in various climates.
\end{abstract}

Keywords: cassava, dry matter production, dry matter distribution, simulation

\section{Introduction}

Much research has been done on the plant characteristics that determine yield performance in cassava (Mahon et al., 1976; Aslam et al., 1977; Connor et al., 1981; Cock, 1983; Howeler \& Cadavid, 1983). Although it is a reasonably well investigated crop, very few efforts have been made to incorporate the knowledge acquired into growth models, as has been done for many crops of the temperate regions. As growth models help to understand the physiology of the whole plant, they can aid breeders in selecting for plant characteristics that are important for optimal growth and yield, and can be used by agronomists when analysing and designing field experiments.

A common and simple model of crop growth (Monteith, 1977) is to express crop growth as the integral of intercepted light multiplied by a factor for converting intercepted PAR (photosynthetically active radiation, $400-700 \mathrm{~nm})$ to dry matter $(\alpha, \mathrm{g}$ 
DM per MJ PAR intercepted):

$$
Y=\alpha \int_{t_{l}}^{t_{2}} I_{\mathrm{o}} \exp (-K L) \mathrm{d} t
$$

where:

$Y=$ crop dry weight increase between time $t_{1}$ and time $t_{2}$

$I_{0}=$ the incident flux of photosynthetically active radiation

$K=$ extinction coefficient

$L=$ leaf area index

Veltkamp (1986) analysed field experiments on the basis of values of $\alpha$.

This type of model shows the importance of both radiation level and soil coverage by the canopy. It may serve as a benchmark relationship for validating more complicated models.

More complicated models must be developed carefully, taking care that they are not unnecessary detailed yet clarify the contribution of processes that underlie cultivar differences.

A summary model of growth of cassava was developed at CIAT (Cock et al., 1979). Its structure is based on the assumption that photosynthetically derived assimilates that are not needed for top growth are distributed to the fibrous and storage roots. Leaf area index (LAI) is computed with formulae describing canopy development, and daily total dry matter increase is calculated using a regression equation relating crop growth to LAI. Although the model can be used to evaluate various cultivar characteristics, the equations are regression formulae derived from experiments at CIAT and are only valid for the climatological conditions prevailing there.

To develop a growth model for cassava with wider applicability, the dry matter production and distribution in field experiments by Veltkamp (1986) were simulated in this study by means of the SUCROS model (Simple and Universal CROp growth Simulation model; Penning de Vries \& van Laar, 1982). SUCROS is derived from extensive growth models and has been used to model the growth of various crops. The model describes basic physiological processes, can be used for different climates, and can describe the growth of many different crops and cultivars if its parameters are changed accordingly.

A basic aspect of the SUCROS model is the assumption that partitioning of dry matter over various plant organs is constant during long periods of growth. This was found by Brouwer (1963) for many plant species. Boerboom (1978) showed that during the root filling stage of cassava too, a constant fraction of dry matter increase is partitioned to the storage roots. This was confirmed by Veltkamp (1986) who, in addition, found that dry matter partitioning was also constant in the period before root filling.

The simulation study was carried out using data from four experiments conducted at the CIAT experimental station at Palmira, Colombia, which have been described in detail elsewhere (Veltkamp, 1986). The model identifies critical parameters for 
dry matter production. Possible suboptimal growth conditions are signalled by differences between measured and simulated growth.

\section{Experimental conditions and data}

The experimental conditions and data will merely be summarized here.

\section{Climate, soil and cultivars}

The experiments were conducted at CIAT, Palmira $\left(3^{\circ} 31^{\prime} \mathrm{N}, 76^{\circ} 21^{\prime} \mathrm{W}, 1000 \mathrm{~m}\right.$ above sea level), between December 1978 and March 1981. The climate is equable with a generally high amount of sunshine (Fig. 1). The soil has been classified as a Mollisol.

The cultivars MCol 1684, MVen 77, MPtr 26 and MCol 22 were grown for 362 days in Experiment 1 and for 178 days in Experiment 2. In Experiment 3 (duration 303 days) the cultivars MCol 1684, Mptr 26 and MMex 59 formed the control treatment of a grafting experiment. In Experiment 4 the cultivars MCol 1684, MPtr 26 and MCol 22 were grown for 272 days.

Planting density was $1 \mathrm{~m} \times 1 \mathrm{~m}$. The fields were fertilized with $100 \mathrm{~kg} \mathrm{ha}^{-1}$ of $\mathrm{N}$, $\mathrm{P}_{2} \mathrm{O}_{5}$ and $\mathrm{K}_{2} \mathrm{O}$ in the form of NPK 15-15-15 composite fertilizers, shortly after planting. The fields were weeded and irrigated when necessary. Nevertheless in Exp. 1, plants suffered water stress in the dry period 190 to 210 days after planting.

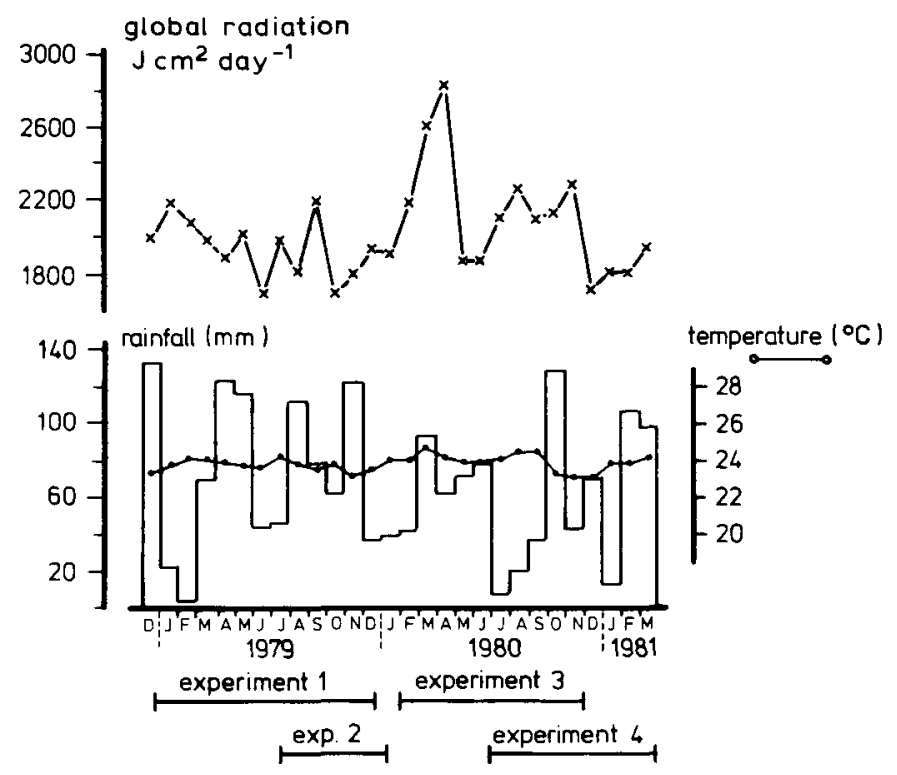

Fig. 1. Mean monthly total radiation $\left(\mathrm{J} \mathrm{cm}^{-1}\right.$ day $\left.{ }^{-1}\right)$, temperature $\left({ }^{\circ} \mathrm{C}\right)$, and rainfall $\left(\mathrm{mm} \mathrm{month}^{-1}\right)$ during the four experiments at CIAT, Palmira (adapted from Veltkamp, 1986). 


\section{Determination of growth parameters}

A large number of measurements of plant growth were carried out regularly in all four experiments, including measurement of light interception, total leaf area and dry weights of different plant parts (including the fallen leaves). Plant samples were taken in Experiment 1 at 62, 123, 185, 241, 304 and 362 days after planting (DAP), in Experiment 2 at 48, 73, 88, 117 and 178 DAP, in Experiment 3 at 138, 185, 246 and 303 DAP, and in Experiment 4 at 51, 86, 177 and 272 DAP. Leaf samples were taken once per experiment for a diagnosis of the nutritional status of the crop. The concentrations of calcium were determined in attached and fallen leaves in order to estimate the amount of relocation of dry matter from fallen leaves.

Maximum crop growth rates were $100-130 \mathrm{~kg} \mathrm{DM} \mathrm{ha}^{-1} \mathrm{day}^{-1}$. The total dry weight at which root thickening apparently started varied from 1100 to $3600 \mathrm{~kg}$ $\mathrm{ha}^{-1}$. The fraction of total dry matter increase allocated to root growth after root thickening had started, varied from 0.39 to 0.61 , but was 0.28 for cultivar MMex 59 .

The leaf area indices generally increased during the first 3 months after planting, reaching a value of 2.5-5, and declined after 4-5 months of growth. In Exp. 1, a new increase followed after a significant leaf fall at 6 months after planting (Fig. 2).

The photosynthesis-light response curve was determined for individual leaves of the cultivars MCol 1684, MVen 77, MPtr 26 and MCol 22 in a pot experiment. To this end, the dark respiration and photosynthetic rates were measured at 5 light intensities ranging from 22 to $327 \mathrm{~J} \mathrm{~m}^{-2} \mathrm{~s}^{-1} \mathrm{PAR}$. A negative-exponential function

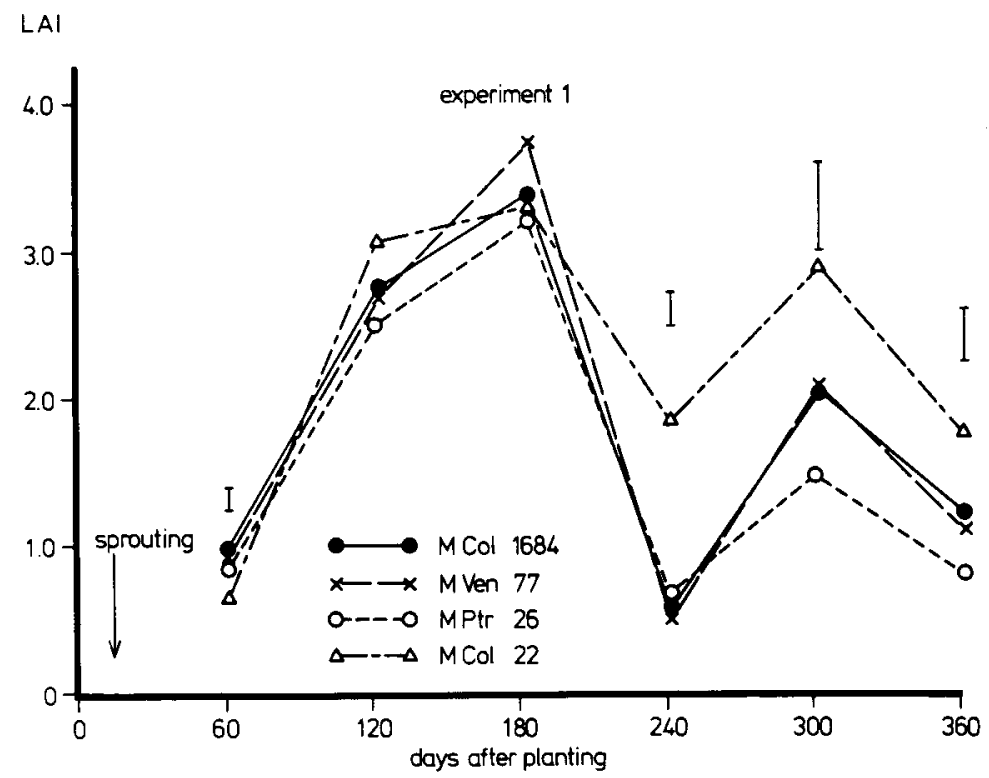

Fig. 2. Leaf area index of the cultivars MCol 1684, MVen 77, MPtr 26 and MCol 22 in Exp. 1 (362 days) (from Veltkamp, 1986). 
relating gross photosynthesis to absorbed radiation was fitted through the data. The curve of this function is characterized by the initial slope at low light intensities, i.e., the efficiency of light utilization (EFF value), and by the upper limit, the gross photosynthesis at light saturation (AMAX value). The photosynthetic efficiency ranged from 9 to $12.4 \mathrm{~g} \mathrm{CO}_{2}$ (MJ PAR) $^{-1}$ and maximum rate of gross photosynthesis varied between 29.5 and $32.5 \mathrm{~kg} \mathrm{CO}_{2} \mathrm{ha}^{-1} \mathrm{~h}^{-1}$. These values are characteristic for a $\mathrm{C}_{3}$ species.

Light intensity was measured regularly above the canopy (one measurement per plot) and beneath the canopy at about $20 \mathrm{~cm}$ above the soil surface (four measurements per plot). The data on light interception were used directly in the model to compute canopy photosynthesis. When the regression coefficient between light interception and LAI (the extinction coefficient) was used to calculate light interception, dry matter yields deviated less than $2 \%$.

\section{Application of the model}

The SUCROS model had to be modefied for cassava, as the parameters for photosynthesis, assimilate conversion, dry matter partitioning and respiration are crop and cultivar-specific. Special attention was paid to relocation of dry matter from falling leaves, an important process in perennial plants.

The computation of the main variables and parameters in the model is described below. The model is schematized in Figure 3.

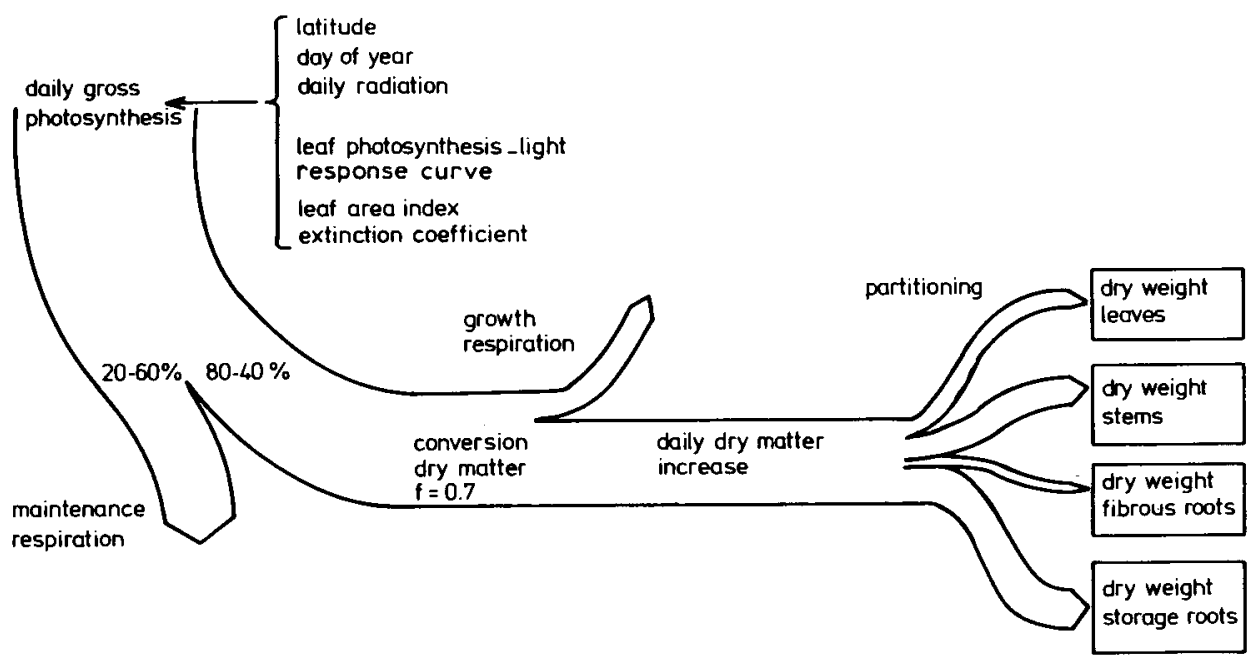

Fig. 3. Diagram of the dry matter production in the cassava growth model. Gross photosynthesis and respiration are expressed as $\mathrm{kg} \mathrm{CH}_{2} \mathrm{O} \mathrm{ha}^{-1}$ day- $^{-1}$, and dry matter increase as $\mathrm{kg}$ DM dry matter haday ${ }^{-1}$. An average loss of $20-60 \%$ of the daily gross photosynthetic products (expressed as $\mathrm{CH}_{2} \mathrm{O}$ ) by maintenance respiration and a factor $(F)$ of 0.7 for conversion of glucose to dry matter are typical for the experiments. 


\section{Modification of the model}

\section{Photosynthesis}

The calculation of daily crop photosynthesis was based on data of latitude, radiation, LAI and the photosynthesis-light response curve of individual leaves, as described by Penning de Vries \& van Laar (1982).

\section{Respiration}

A certain amount of the carbohydrates (they are expressed as glucose) produced by photosynthesis is consumed by non-photosynthetic respiration. Respiration losses can be subdivided into respiration for growth and respiration for maintenance processes of the plant.

Growth respiration. The amount of glucose needed for conversion into 1 gram of dry matter was calculated per organ, based on the composition of leaves, stems and roots of the cultivars in Experiment 1. The factors for converting glucose to proteins, fats, lignine, minerals, organic acids and carbohydrates were derived from Penning de Vries \& van Laar (1982). It was assumed that in cassava, crude fiber consists of $80 \%(\mathrm{w} / \mathrm{w})$ carbohydrates and $20 \%(\mathrm{w} / \mathrm{w})$ lignine, and that minerals constitute $60 \%$ of the ash (cf. Penning de Vries et al., 1983). On this basis, the conversion factors of dry matter of leaves, stems, primary roots and storage roots were calculated to be $0.63,0.72,0.72$ and $0.78 \mathrm{~g}$. respectively. The factors varied less then 0.01 between cultivars. These factors were then weighted with the coefficients for partitioning of dry matter to the organs, so that the conversion factor of glucose to total dry matter could be calculated. This conversion factor was $0.66-0.68$ for dry matter produced before the root filling stage, and 0.72-0.74 during the root filling stage.

Maintenance respiration. The daily maintenance costs of an organ of the plant were computed by multiplying the specific maintenance coefficient (m.c., $\mathrm{kg}$ glucose $\mathrm{kg}$ DM) ${ }^{-1}$ day $^{-1}$ ) by the dry weight of the organ. Only data of maintenance respiration of cassava storage roots could be found in literature (Mahon et al., 1976). The rates of respiration of the stems had to be estimated roughly.

For cassava, a perennial plant, the SUCROS values of the maintenance coefficients for stems and roots (i.e., $0.015 \mathrm{~kg}$ glucose $\left(\mathrm{kg} \mathrm{DM}^{-1} \mathrm{day}^{-1}\right.$ ) had to be adjusted, because the standard version of SUCROS contains parameter values for annual plants. Application of these standard values would mean that with a photosynthetic rate less than $300 \mathrm{~kg}$ glucose ha-1 day-1 $^{-1}$ all the glucose would be consumed by the maintenance respiration of $20 \mathrm{t}$ of stems and roots. Using the respiration data of Mahon et al. (1976) the m.c. of the storage roots was estimated to be $0.004 \mathrm{~kg}$ glucose $(\mathrm{kg} \mathrm{DM})^{-1} \mathrm{day}^{-1}\left(\right.$ at $25^{\circ} \mathrm{C}$ ). The m.c. of the fibrous roots was assumed to be $0.015 \mathrm{~kg}$ glucose $(\mathrm{kg} \mathrm{DM})^{-1}$, the same as applied in SUCROS. The value of the m.c. of the stems can be considered to be much lower than the m.c. of annual plant stems (i.e. $0.015 \mathrm{~kg}$ glucose $\left(\mathrm{kg} \mathrm{DM}^{-1} \mathrm{day}^{-1}\right.$ ) as cassava stems are much more woody and have much lower metabolic activity per unit of dry weight 
Table 1. Estimated coefficients for maintenance respiration of cassava organs (kg glucose (kg DM)-1 day-1).

\begin{tabular}{ll}
\hline Leaves & 0.035 \\
Stems. & 0.005 \\
Fibrous roots & 0.015 \\
Storage roots & 0.004 \\
\hline
\end{tabular}

than those of annual plants (the m.c. could be roughly 50-75 \% lower; F. W. T. Penning de Vries, pers. comm., 1984). A more precise value of the m.c. of the stems and a slightly adjusted value of the m.c. of the leaves were found by changing the values of these parameters until simulated yields agreed with measured yields in Experiment 1 (Fig.4). The measured weight of the living leaves was an input to the model for a correct estimation of the maintenance costs. A good fit between measured and simulated dry matter production was obtained for three cultivars. However, with cultivar MCol 22 no close agreement between measured and simulated growth could be attained.

Table 1 shows the values of the m.c.'s used in all experiments and for all cultivars.

$A Q_{10}$ factor of 2 was adopted for maintenance respiration, because this proved to be a satisfactory value in many growth models ( de Wit, 1978; Penning de Vries \& van Laar, 1982).

\section{Relocation}

The amount of dry matter relocated from falling leaves was estimated by comparing the calcium contents in attached and fallen leaves. When dry matter is relocated out of aging leaves, the Ca concentration increases, because this element is hardly redistributed. The average $\mathrm{Ca}$ concentration in fallen leaves in Experiment 1 was $40 \%$ higher than in attached leaves. It was assumed that the relocated material (notably carbohydrates and proteins) could be represented by starch (F. W. T. Penning de Vries, pers. comm., 1984). Thus:

$$
\frac{W_{\mathrm{Ca}}}{W_{\mathrm{fl}}}=1.4 \times \frac{W_{\mathrm{Ca}}}{W_{\mathrm{fl}}+W_{\mathrm{s}}}
$$

where:

$W_{\mathrm{Ca}}=$ weight of calcium

$W_{\mathrm{fl}}=$ weight of fallen leaf

$W_{\mathrm{s}}=$ weight of starch

It was also assumed that the starch weight could be added to the daily photosynthetic products after multiplying by 1.05 (this factor accounts for transformation to glucose and for subtraction of transport costs) (F. W. T. Penning de Vries, pers. comm., 1984). In total, the daily amount of glucose derived from relocation was estimated to be 0.42 times the daily weight of leaves. 
H. GIJZEN, H. J. VELTKAMP, J. GOUDRIAAN AND G. H. DE BRUIJN
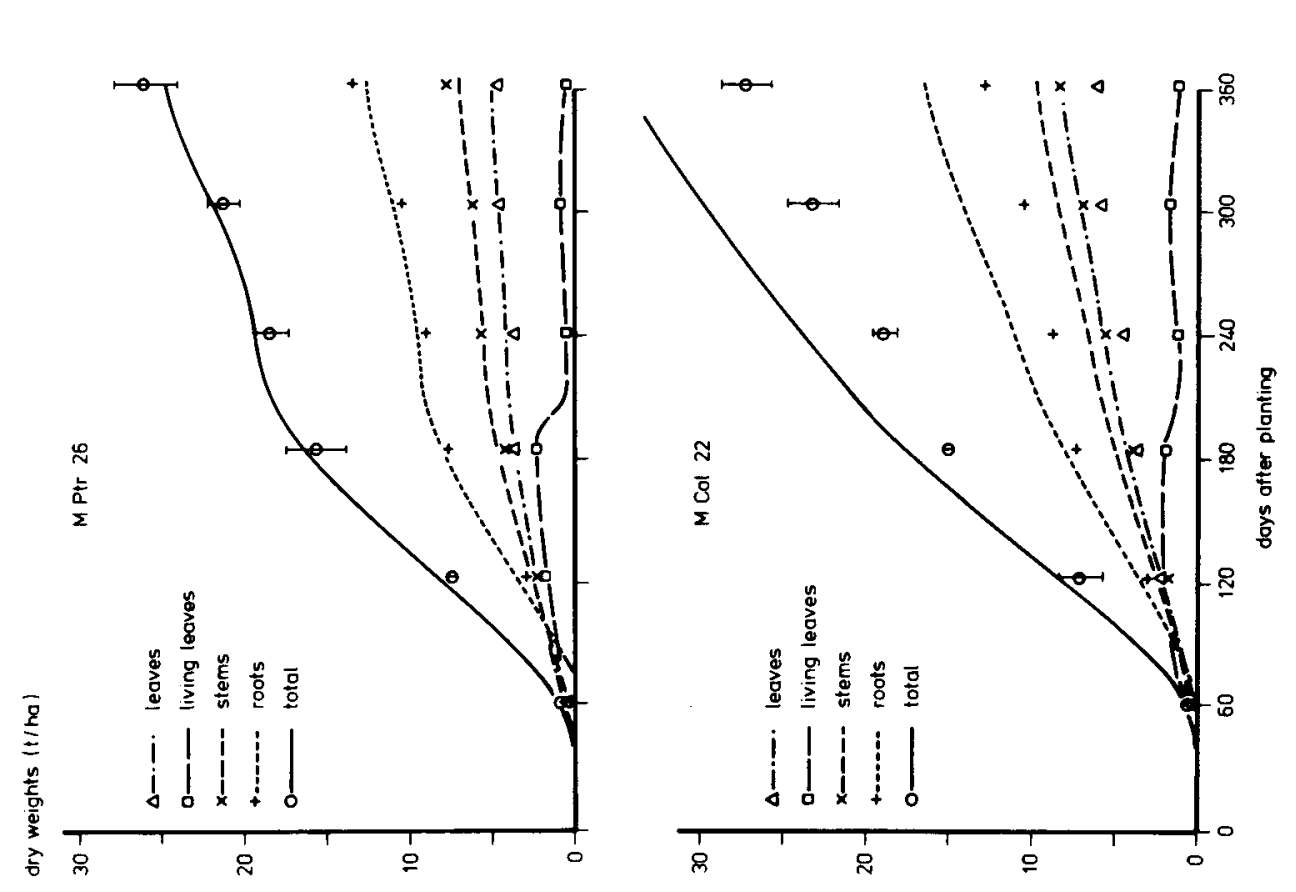

要
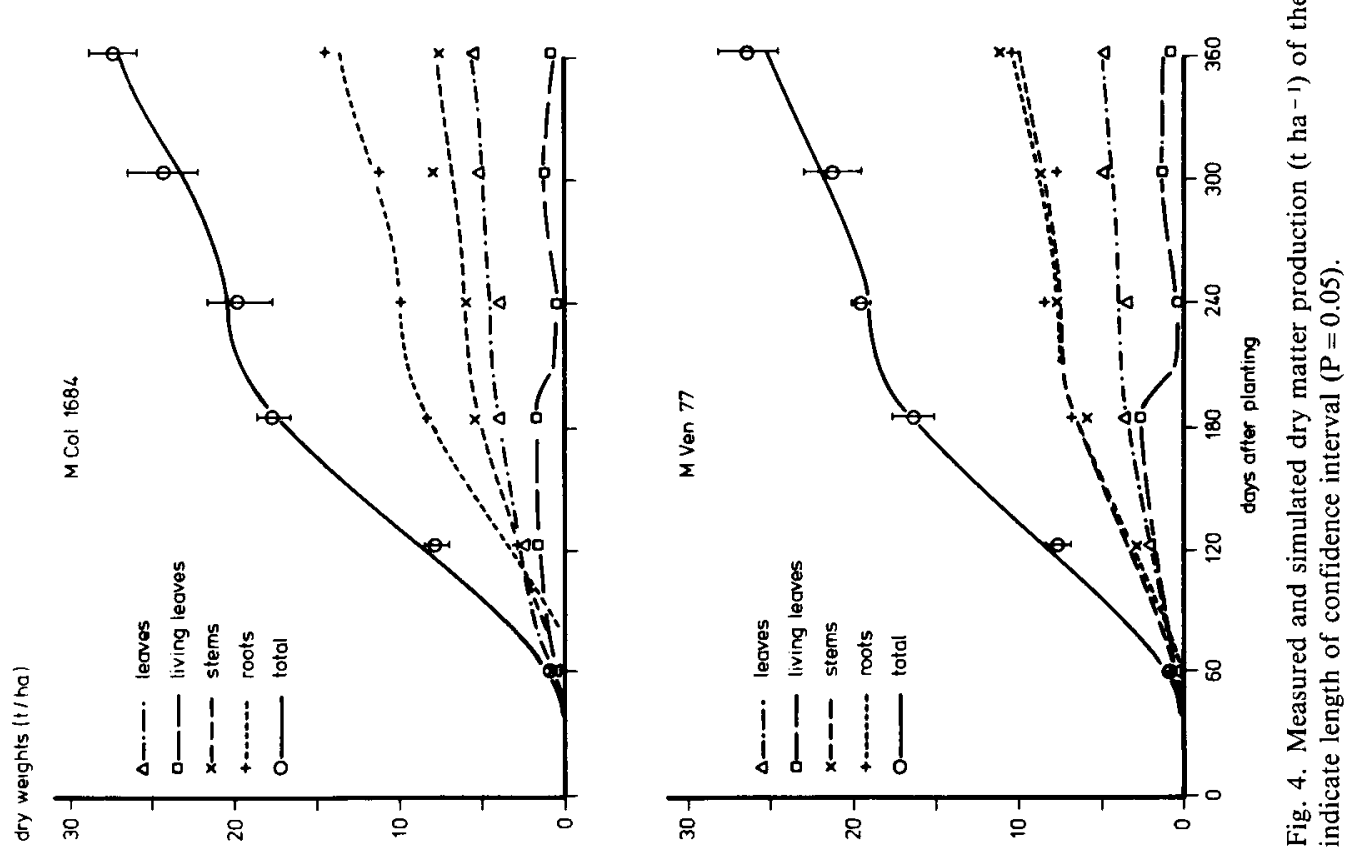

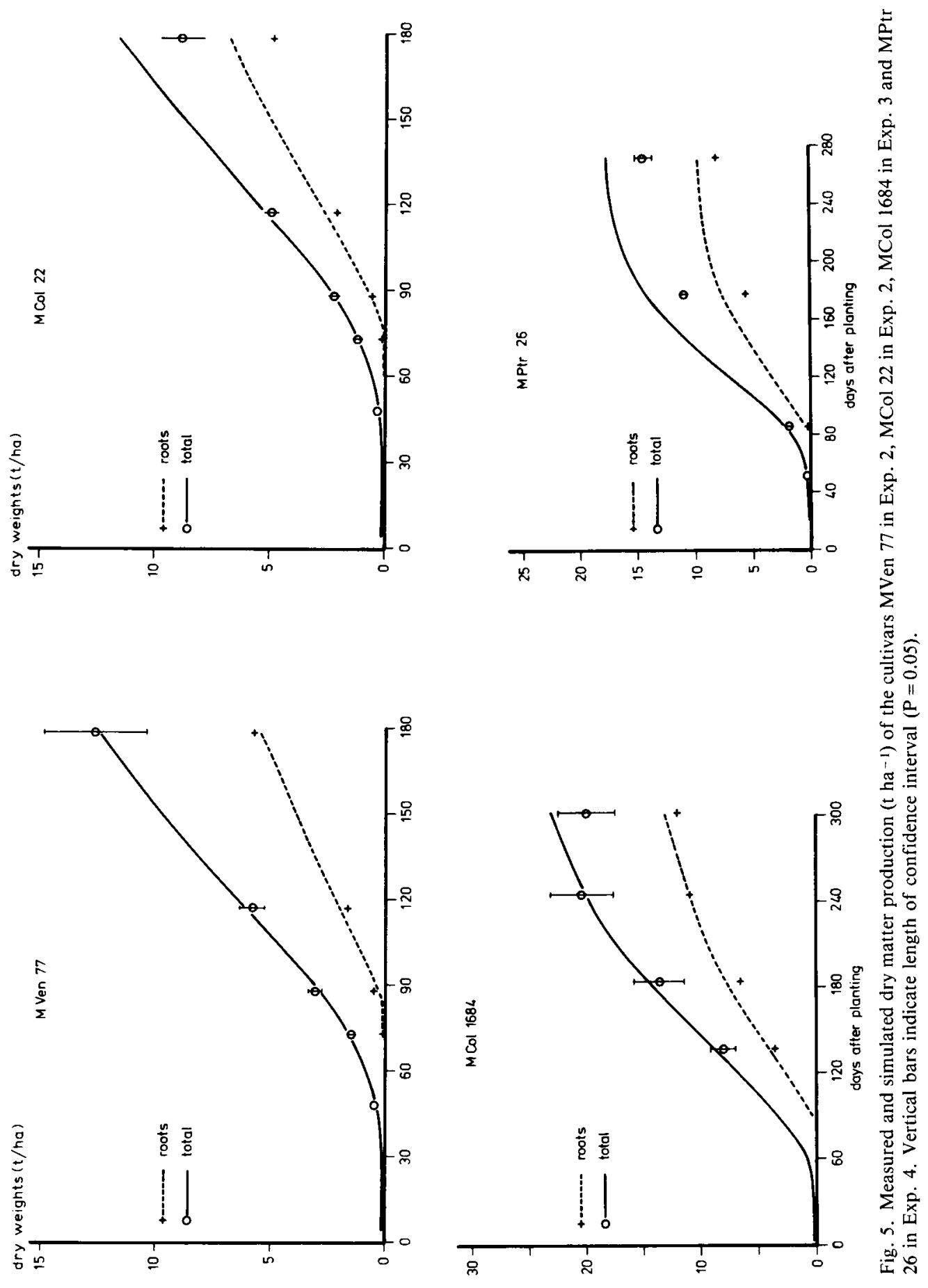

Netherlands Journal of Agricultural Science 38 (1990) 


\section{Validation}

For Experiments 2, 3 and 4 the simulation results were generally satisfactory. Some results are shown in Figure 5. Where simulations differed significantly from measurements, the dry matter production was overestimated. These deviations are discussed below.

For MCol 22 there was good agreement between measured and simulated dry matter production in Experiment 2 until 4 months after planting (Fig. 5). In the last two months of this experiment and in Experiment 4 (not shown), simulation greatly overestimated actual dry matter production. In Experiment 3, some overestimation occurred at the end of the experiment. (See MCol 1684 in Fig. 5). In that period the rate of growth in the field of all three cultivars was significantly less than earlier in the season. In this experiment, the growth of MMex 59 was overestimated by $20 \%$ (not shown). In Experiment 4 the simulated yield of MPtr 26 was considerably higher than the measured yield (36\%) (Fig.5).

\section{Sensitivity analysis}

The importance of several parameters for the dry matter production was tested by changing their values. All runs were done with cultivar MCol 1684 in Experiment 1. The sensitivity of the model output was measured as the percentage change in total simulated dry weight per percentage change of the input parameter (plus or minus $20 \%$ of the standard value, Fig. 6).

The light use efficiency at low light intensity (EFF value) and the photosynthetic rate at light saturation (AMAX value) appear to have a large influence on dry matter production. The influence of the AMAX value on dry matter yield is large, probably because of the low LAI (average 2 - 2.5) of cultivar MCol 1684 in Experiment 1. This low LAI means that a large part of the canopy was nearly light-saturated during much of the growing period.

The relative influence of the extinction coefficient on dry matter production is significant. This is because the LAI was low, especially in the second half of the growing period.

The relative influences of the conversion factors are also significant. However, as a change in the composition of the plant material does not have a large effect on the values of the conversion factors, their importance for determination of yield is not large.

The relative influence of the maintenance coefficients on dry matter production is about the same as that of the conversion factors. However, as plant organ weights as a ratio to total plant weight can vary significantly between cultivars, they are important for determination of crop yield.

Other studies on modelling also found that the m.c. had a large influence on growth (de Wit, 1978, Hunt \& Loomis, 1979).

Increasing or decreasing the average radiation level by $20 \%$, causes the total gross assimilation and total dry matter yield to increase by 6-7 \% or decrease by $10 \%$, respectively (assuming that the dry matter partitioning will be the same at these radiation levels). 
Factor

Rate of photosynthesis at light sat.

Eff. of light utilization in photosynth

Extinction coefficient

Maintenance coef. for leaves

Maintenance coef. for stems

Mcintenance coef. for storage roots

Conversion factor for leaves

Conversion factor for stems

Conversion factor for storage roots

Initial start of starch accumulation

Radiation tevel
Relative influence

0.5

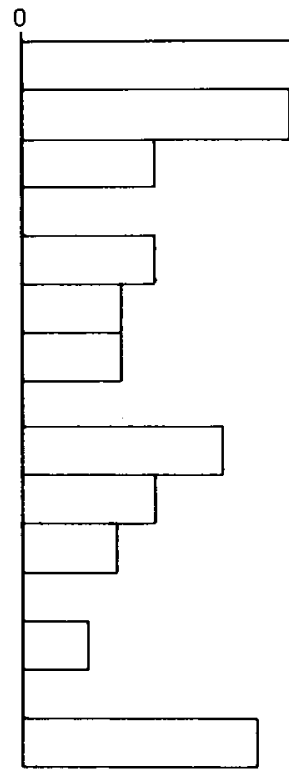

10

Fig. 6. Results of the sensitivity analysis of the simulation of growth of cultivar MCol 1684 in Exp. 1 . The relative influence of changing the values of some variables and parameters on total dry matter yield is calculated (i.e., $\delta \mathrm{TWT} / \mathrm{TWT}$ divided by $\delta \mathrm{P} / \mathrm{P}$ (TWT $=$ total dry weight, $\mathrm{P}=$ value of parameter or variable)).

\section{Discussion}

\section{General performance}

In Experiment 1, agreement between experiment and simulation could be obtained by adjusting the values of the maintenance coefficients of leaves and stems. Although the procedure reduces the independence of the simulation, the agreement obtained is not trivial because the maintenance coefficients were kept constant, and also equal for all cultivars and experiments. With the other experiments, the discrepancy between simulated and measured dry matter production varied from very little to significant.

The reasons for the disagreement in the case of cultivar MCol 22 are not clear. The overestimation of cultivar MPtr 26 in Experiment 4 could be due to the specific growth conditions in the field. In this experiment the mineral contents were below the level that is considered to be optimal for growth (Howeler, 1980), and the plants of all cultivars were shorter than in the other experiments. This indicates that the growing conditions were not optimaal (Veltkamp, 1986).

In the descriptive formulae for computation of the canopy assimilation rate, it is implicitly assumed that the assimilation rate at light saturation (AMAX value) does 
not decrease with age of the plant or with age of the leaves. Cock (CIAT, 1978) found that the maximum photosynthetic rates of individual leaves increased until 14 days after leaf emergence, and remained at a constant level until 100 days of leaf age. This tendency was observed also by Tsuno et al. (1983). However, Aslam et al. (1977) found that the assimilation rate at intermediate light intensities did decrease with age of the leaf, but not with age of the plant.

\section{Crop light use efficiency}

As shown by Veltkamp (1986), the average light use efficiency $\alpha$ (g DM (MJ intercepted PAR) ${ }^{-1}$ ) decreased with longer growing periods (Fig.7). A possible cause is temporary water stress (Veltkamp, 1986). Nutrient shortage was unlikely (with the exception of Experiment 4 ) because the plots concerned were well fertilized. Simulation results suggested that the decrease of $\alpha$ was largely the result of the fact that the fraction of assimilates consumed by maintenance respiration rose considerably, especially after growth periodes longer than 6 months (Fig.8). As partitioning was constant in time, the rate of dry matter allocation to the leaves would also be less. Indeed, the leaf formation rate did decrease in the experiments with long growing periods, and due to a more or less constant leaf longevity the LAI started to decline as well.

\section{Respiration}

The estimate of the maintenance coefficient for the leaves seemed to compare

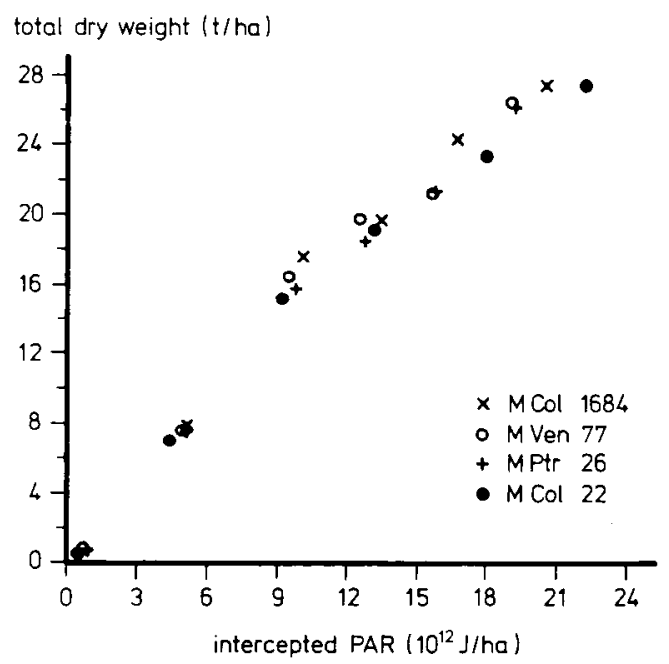

Fig. 7. Relation between measured dry matter production (t ha- ${ }^{-1}$ ) and intercepted photosynthetically active radiation (PAR, $106 \mathrm{MJ} \mathrm{ha}^{-1}$ ) for four cultivars in Exp. 1. 
favourably with the measured dark respiration of the leaves. With a maintenance coefficient of $0.035 \mathrm{~kg} \mathrm{CH}_{2} \mathrm{O}(\mathrm{kg} \mathrm{DM})^{-1}$ day $^{-1}$ and a specific leaf area of $14-16 \mathrm{~m}^{2}$ leaf $\mathrm{kg}^{-1}$, the maintenance respiration is $1.3-1.5 \mathrm{~kg} \mathrm{CO}_{2}$ (ha leaf) ${ }^{-1} \mathrm{~h}^{-1}$. The dark respiration was found to be $1.7-2.0 \mathrm{~kg} \mathrm{CO}_{2}$ (ha leaf) ${ }^{-1} \mathrm{~h}^{-1}$ at $25^{\circ} \mathrm{C}$ (Veltkamp, 1986). However, this measured respiration rate does not only reflect maintenance respiration, but is also connected with processes of growth and translocation of assimilates (de Wit, 1978).

The amount of $\mathrm{CO}_{2}$ lost by respiration after assimilation is considerable. Based on the average composition of the newly formed dry matter, in Experiment 1 the calculated growth respiration decreased from 55 to $25 \mathrm{~kg} \mathrm{CO}_{2} \mathrm{ha}^{-1} \mathrm{day}^{-1}$ in the period 90-180 days after planting. In this same period the rate of maintenance respiration increased from 75 to $200 \mathrm{~kg} \mathrm{CO}_{2} \mathrm{ha}^{-1}$ day-1, thus the total respiration was 130-225 $\mathrm{kg} \mathrm{CO}_{2} \mathrm{ha}^{-1} \mathrm{day}^{-1}$. As a result of respiration, 33 to $58 \%$ of the average

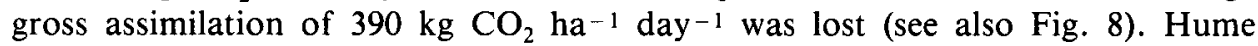
(1975) estimated that 6-month-old cassava plants lost $40 \%$ of the assimilated $\mathrm{CO}_{2}$ in the field in 1 week after labelling with ${ }^{14} \mathrm{C}$. Leaf fall was not considered to con-

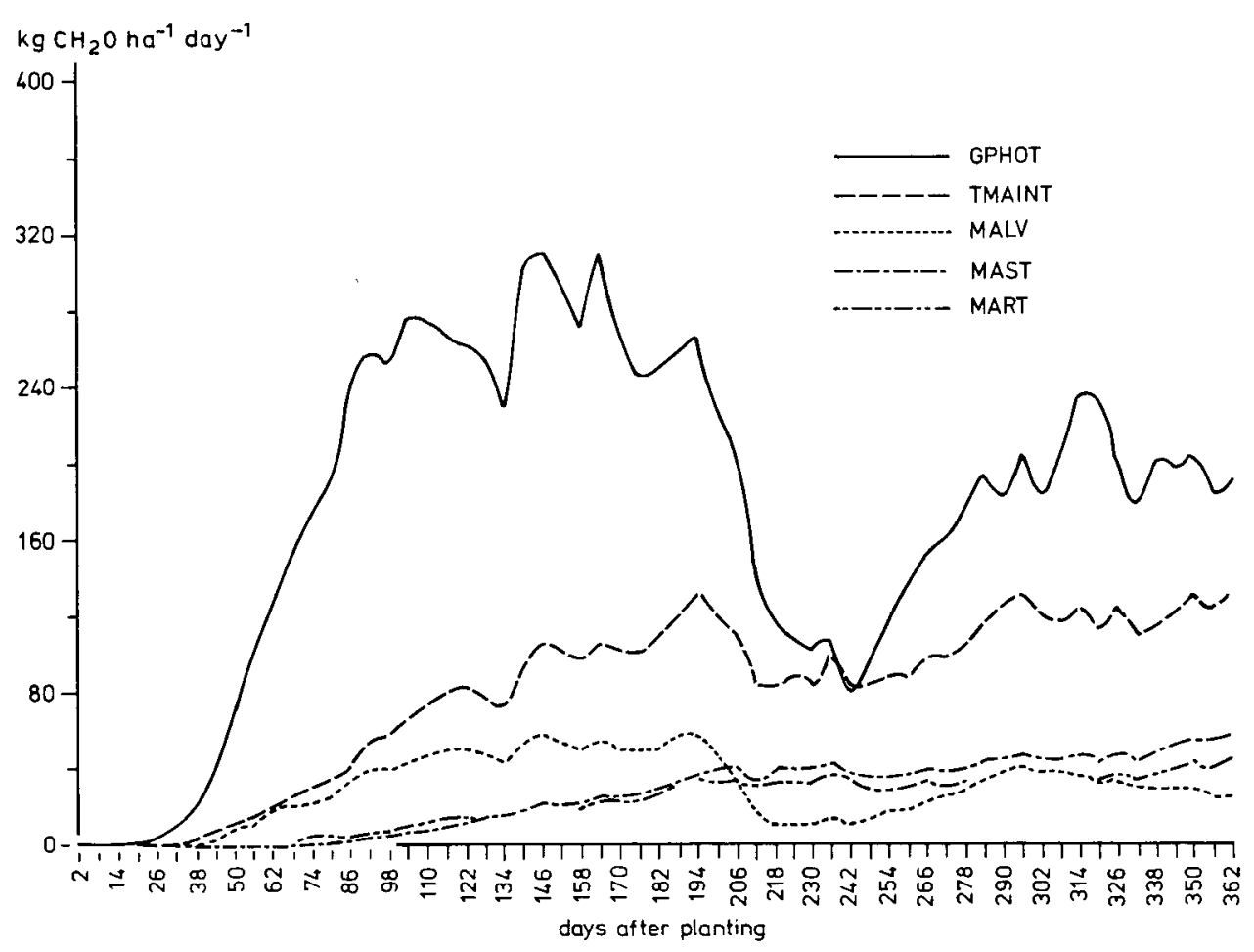

Fig. 8. Simulated daily rates $\left(\mathrm{kg} \mathrm{CH}_{2} \mathrm{O}\right.$ ha-1 day-1) of gross photosynthesis (GPHOT), total maintenance respiration (TMAINT) and maintenance respiration of leaves (MALV), stems (MAST) and roots (MART) for MCol 1684 in Exp. 1. 
tibute significantly to the loss. A comparable respiration was found by Mahon et al. (1976) with cassava plants 4-9 months old. They calculated that the plants, which were grown in a climate chamber at $29 / 24{ }^{\circ} \mathrm{C}$ day/night temperature, lost 37 to $53 \%$ of the assimilates by respiration.

Although the model results for respiration were well within such experimental constraints, the maintenance coefficients were not determined accurately enough and are still a weak part in the model. Perhaps the overestimation of the dry matter production of MMex 59, a cultivar with significantly more top growth that the other cultivars, is due to a deviating maintenance coefficient. More accurate estimates of the values of the maintenance coefficients are badly needed.

\section{Usefulness of the model}

The validity of the model should be tested further under other climatological conditions. Only data from CIAT (Cali, Colombia) were used in present study, and it is necessary to test the model for other locations that have optimal conditions for cassava growth.

Assuming its validity, the model can be used for comparing cultivar performance and for comparing performance of a single cultivar in different climates. At present, its applicability is limited. The model assumes that growing conditions are optimal, whereas cassava is commonly grown under marginal conditions. To be applicable to the latter conditions, the model must first be validated more for optimal conditions, and subsequently extended to describe the effects of water and nutrient stress on growth. As the model used here describes basic physiological processes, it is a good starting point for a cassava model that is applicable for many diverse conditions.

\section{References}

Aslam, M., S. B. Lowe \& L. A. Hunt, 1977. Effect of leaf age on photosynthesis and transpiration of cassava (Manihot esculenta). Canadian Journal of Botany 55: 2288-2295.

Boerboom, B. W. J., 1978. A model of dry matter distribution in cassava (Manihot esculenta Crantz). Netherlands Journal of Agricultural Science 26: 267-277.

Brouwer, R., 1963. Some aspects of the equilibrium between overground and underground plant parts. Jaarboek Instituut voor Biologisch en Scheikundig Onderzoek (IBS), p. 31-39.

CIAT (Centro Internacional de Agricultura Tropical), 1976, 1979. Annual Reports 1975, 1978. Cali, Colombia.

Cock, J. H., 1983. Cassava. Proceedings Symposium on Potential Productivity of Field Crops under Different Environments, p. 341-359. International Rice Research Institute, Manila, Philippines.

Cock, J. H., D. Franklin, G. Sandoval \& P. Juri, 1979. The ideal cassava plant for maximum yield. Crop Science 19: 271-279.

Connor, D. J., J. H. Cock \& G. E. Parra, 1981. Response of cassava to water shortage. I. Growth and yield. Field Crops Research 4: 181-200.

Howeler, R. H., 1980. Soil related cultural practices for cassava. In: Weber, E. J., J. C. Toro \& M. Graham (Eds), Cassava cultural practices, p. 59-69. Proceedings of a workshop, Salvador, Bahia (Brasil), International Research Development Centre, Ottawa. IDRC 15le.

Howeler, R. H. \& L. F. Cadavid, 1983. Accumulation and distribution of dry matter and nutrients during a 12-month growth cycle of cassava. Field Crops Research 7: 123-139. 
Hunt, W. F. \& R. S. Loomis, 1979. Respiration modelling and hypothesis testing with a dynamic model of sugar beet growth. Annals of Botany 44: 5-17.

Hume, D. J., 1975. Translocation of ${ }^{14} \mathrm{C}$-labelled photosynthetic assimilates in cassava (Manihot esculenta Crantz). Ghana Journal of Agricultural Science 8: 69-75.

Mahon, J. D., S. B. Lowe \& L. A. Hunt, 1976. Photosynthesis and assimilate distribution in relation to yield of cassava grown in controlled environments. Canadian Journal of Botany 54: 1322-1331.

Monteith, J. L., 1977. Climate and the efficiency of crop production in Britain. Philosophical Transactions of the Royal Society, London, B281: 277-294.

Penning de Vries, F. W. T. \& H. H. van Laar, 1982. Simulation of plant growth and crop production. Simulation Monographs, Pudoc, Wageningen, $307 \mathrm{pp}$.

Penning de Vries, F. W. T., H. H. van Laar \& M. C. M. Chardon, 1983. Bioenergetics of growth of seeds, fruits, and storage organs. Proceedings Symposium on the Potential Productivity of Field Crops under Different Environments, p. 37-60. International Rice Research Institute, Manila, Philippines.

Tsuno, Y., T. Taniyama \& H. Suprapto, 1983. The photosynthesis and estimation of productivity of cassava. Japanese Journal of Crop Science 52: 484-492.

Veltkamp, H. J., 1986. Physiological causes of yield variation inrcassava (Manihot esculenta Crantz). Wageningen Agricultural University Papers 85-6. Wageningen Agricultural University, Wageningen, $103 \mathrm{pp}$.

Wit, C. T. de, 1978. Simulation of assimilation, respiration and transpiration of crops. Simulation Monographs, Pudoc, Wageningen, 140 pp. 